\title{
Rear earth elements distribution in marine sediments of Malaysia Coasts
}

\begin{abstract}
In the east coast Peninsular Malaysia region, sediments are transported by several rivers from the east Malaysia into the South China Sea estuary. In the vicinity of the five river estuaries core sediments were collected in order to investigate rare earth elements (REEs) profile. Core sediments were divided into strata of between 2 to $4 \mathrm{~cm}$ intervals and prepared for analyzing by ICP-AES. REE concentrations of $54.3 \mu \mathrm{g} / \mathrm{gr}$ at $24-26 \mathrm{~cm}$ in EC4 increased to $114.1 \mu \mathrm{g} / \mathrm{gr}$ at $20-22 \mathrm{~cm}$ in EC5. The measured concentration of LREEs and Fe normalized enrichment factors indicated that sediments were not enriched with light rare earth elements derived from effluents of anthropogenic activities. Results of the total concentration were used to establish baseline data in environmental pollution assessment and to develop the correlations between the $\mathrm{Ce} / \mathrm{Ce}^{*}$ and $\mathrm{Eu} / \mathrm{Eu}^{*}$ anomalies and the distribution patterns of some light rare earth elements (LREEs) and the heavy rare earth elements (HREEs). The chondrite-normalized ratios of REEs showed LREEs enrichment and flat HREE depletion.
\end{abstract}

Keyword: Enrichment factor; Rare earth elements; Marine sediments; South China Sea; Shale average 